\section{Elaine Thumé'}

Luiz Augusto Facchini"

Elaine Tomasi"II

Lúcia Azambuja Saraiva Vieiralv

\section{Home health care for the elderly: associated factors and characteristics of access and health care}

\begin{abstract}
OBJECTIVE: To assess factors associated with home health care for the elderly and its characteristics based on different care models, the Family Health Strategy and traditional primary care.
\end{abstract}

METHODS: A population-based cross-sectional study was conducted in a representative sample of 1,593 individuals aged $\geq 60$ years living in the urban area of the city of Bagé, Southern Brazil, in 2008. A multistage sampling was carried out. Data was collected during individual interviews about access to services, providers' involvement, users' satisfaction and health status after care. Poisson regression model was used for estimating crude and adjusted prevalence ratios, their related 95\% confidence intervals and p-values (Wald test).

RESULTS: Home health care was statistically associated with prior history of stroke, signs of dementia and disability in activities of daily living. The family was requested $75 \%$ of home care visits. Medical doctors provided most of the care in traditional primary care settings while nursing staff provided most care within the Family Health Strategy. Approximately $78 \%$ of the elderly received care within 24 hours after the request and $95 \%$ of them positively evaluated the care received. Two thirds of the elderly reported improved health status.

CONCLUSIONS: The variables associated with home health care were consistent with fragility indicators included in the Brazilian National Health Policy for the Elderly, reinforcing the role of this strategy for promoting equitable health care to elderly population. Users' satisfaction and the positive impact on their health status confirm home as a setting for providing care.

DESCRIPTORS: Aged. Home Nursing. Family Health Program. Health Services Accessibility. Primary Health Care. Cross-Sectional Studies.

\section{INTRODUCTION}

The implementation of the Family Health Strategy (FHS) in Brazil is an attempt to reorganize primary care, ${ }^{22}$ improve access to health care and restore home as a setting for providing care. ${ }^{12,15}$ Home health care can reduce hospital costs and humanize health practices. ${ }^{1,5} \mathrm{Chronic}$ non-communicable diseases associated with population aging can cause limitations with temporary or permanent functional disabilities. ${ }^{4}$ It is thus a challenge for managers and society to find alternative care strategies to meet specific demands of the elderly and their families. ${ }^{3,9}$

Despite discussions and the formulation of specific policies for the elderly, changes are still incipient. ${ }^{21}$ The release of guidelines for elderly primary care 
is an attempt to translate these theoretical discussions into health practices. ${ }^{4}$ Although some qualitative studies have explored home health care and hospital care at home, ${ }^{6,19}$ in the scope of population there remain gaps on factors associated with care of the elderly at home, access to care and involvement of health providers in these care services.

The present study aimed to assess factors associated with home health care for the elderly and its characteristics based on different care models, the FHS and traditional primary care.

\section{METHODS}

Population-based cross-sectional study conducted from July to November 2008. The sample consisted of individuals aged 60 or older living in defined geographical areas of primary health care services in the urban area of the city of Bagé, Southern Brazil. In 2006 the population of this municipality was 122,461 inhabitants, $82 \%$ of them living in the urban area. ${ }^{a}$ In 2008, there were 15 FHS units with a total of 19 teams covering $51 \%$ of the city's urban population. Five care units followed the traditional primary care model covering the remaining $49 \%$ of the population. The FHS has been recently implemented in the city and the first team started its operation in 2003.

For studying home health care and its associated factors, it was set a sample of 1,530 individuals with $95 \%$ confidence interval and $80 \%$ statistical power to detect a minimum relative risk of 1.5 for exposures affecting up to $4 \%$ of the population. The final sample size included a $10 \%$ increase to compensate for eventual losses and refusals, 15\% for confounders and a design effect of around 1.3.

The sample was drawn from urban districts within the coverage area of primary care units. First, there were defined geographical areas of each primary care unit and then they were divided into microareas and its blocks were numbered. The starting point of data collection was randomly selected in each block. Households located on the left were considered eligible. One in every six households was selected for sample dispersion in the area. All elderly living in a household were invited to participate in the study. When it was not possible to conduct an interview after three attempts on different days and times, it was considered a loss/ refusal. No replacements were allowed.

A pilot study was carried out to test a pre-coded structured questionnaire. For respondents with partial disability, the questionnaire was administered to a family or primary caregiver. For those respondents with total disability, questions requiring self-reporting were not included.
Home health care - the dependent variable - was defined as a set of services provided at home by health care providers for giving therapeutic support to the elderly and their families. The following question was asked: " $<$ In the last three months $>$ did you receive care at home provided by any of these health providers: doctor? (yes/no); nurse? (yes/no); social worker? (yes/ no); physical therapist? (yes/no)".

Demographic and socioeconomic variables studied were sex, age (60-74 years; 75 years or older), marital status (married or living with partner; widowed; divorced or never married); literate (yes, no); per capita income (in monthly minimum wages [MMWs]: $\leq 1 ;>1$ and $<3 ; \geq 3$ ) and private health insurance (yes, no). The following variables were used as indicators of morbidity: history of falls in the last year (yes, no); medical diagnosis of hypertension (yes, no); diabetes (yes, no); stroke (yes, no); and cancer (yes, no). The results of Mini-Mental State Examination (MMSE) for screening signs of dementia were categorized into presence or absence based on the level of education. ${ }^{7}$ The Geriatric Depression Scale (GDS) was used to assess the presence of depressive symptoms and the results were categorized as: present (score 0-5), and absent (score $\geq 6$ ) ${ }^{18}$ Functional disability was assessed using Katz et $\mathrm{al}^{10}$ and Lawton \& Brody scales. ${ }^{13}$ The elderly who reported needing help to perform at least one activity were considered disabled. It was also investigated hospitalization in the last four years (none; one; two or more); medical visits in the last three months (none; one; two or more); and if the elderly had been bedridden for the last 30 days (yes, no). Self-perceived health status was categorized as either worse/bad/ regular and good/very good.

For characterizing home health care, it was investigated who requested care (the elderly himself/herself; family; friend or neighbor; community health worker [CHW]); how the request was made (the service was called; family member, friend or neighbor personally went to the service; it asked through $\mathrm{CHW}$ ); waiting time (less than 24 hours; 24 hours or more); health providers involved (doctor; nursing staff; social worker; physical therapist); user's satisfaction with care received (bad; regular; good; very good); and health status after care (remained the same; improved a little; improved a lot; recovered).

The analyses were stratified by area of residence and traditional or FHS care. Poisson regression with robust variance estimates ${ }^{2}$ was used to estimate crude and adjusted prevalence ratios with $95 \%$ confidence intervals $(95 \% \mathrm{CI})$. The adjusted analysis sought to control for potential confounding variables in samelevel variables and among those of previous levels, and all variables with $\mathrm{p} \leq 0.20$ remained in the model. A $5 \%$ statistical significance level was set. Due to losses 
Table 1. Characteristics of the study population according to the model of care. City of Bagé, Southern Brazil, 2008.

\begin{tabular}{|c|c|c|c|c|c|c|}
\hline \multirow{2}{*}{ Variable } & \multicolumn{2}{|c|}{ Traditional care } & \multicolumn{2}{|c|}{ Family Health Strategy } & \multicolumn{2}{|c|}{ Total } \\
\hline & $\mathrm{n}=741$ & $\%$ & $\mathrm{n}=852$ & $\%$ & $\mathrm{n}=1,593$ & $\%$ \\
\hline \multicolumn{7}{|l|}{ Gender } \\
\hline Male & 260 & 35.1 & 333 & 39.1 & 593 & 37.2 \\
\hline Female & 481 & 64.9 & 519 & 60.9 & 1000 & 62.8 \\
\hline \multicolumn{7}{|l|}{ Age (years) } \\
\hline $60-74$ & 483 & 65.2 & 613 & 72.0 & 1096 & 68.8 \\
\hline 75 or more & 258 & 34.8 & 239 & 28.0 & 497 & 31.2 \\
\hline \multicolumn{7}{|l|}{ Illiteracy } \\
\hline No & 115 & 15.5 & 264 & 31.0 & 379 & 23.9 \\
\hline Yes & 626 & 85.5 & 588 & 69.0 & 1214 & 76.1 \\
\hline \multicolumn{7}{|l|}{ Marital status } \\
\hline Divorced or single & 109 & 14.7 & 129 & 15.2 & 238 & 15.0 \\
\hline Married & 374 & 50.6 & 442 & 51.9 & 816 & 51.2 \\
\hline Widowed & 257 & 34.7 & 281 & 32.9 & 538 & 33.8 \\
\hline \multicolumn{7}{|l|}{ Per capita income (MMWs) } \\
\hline$\leq 1$ & 355 & 49.2 & 554 & 66.0 & 909 & 58.2 \\
\hline$>1$ to 3 & 243 & 33.6 & 250 & 29.8 & 493 & 31.6 \\
\hline$>3$ & 124 & 17.2 & 35 & 4.2 & 159 & 10.2 \\
\hline \multicolumn{7}{|l|}{ Private health insurance } \\
\hline No & 404 & 54.7 & 621 & 73.3 & 1025 & 64.6 \\
\hline Yes & 335 & 45.3 & 226 & 26.7 & 561 & 35.4 \\
\hline \multicolumn{7}{|l|}{ Morbidities $^{\mathbf{a}}$} \\
\hline Hypertension & 414 & 55.9 & 467 & 54.8 & 881 & 55.3 \\
\hline Diabetes & 97 & 13.1 & 144 & 16.9 & 241 & 15.1 \\
\hline Stroke & 70 & 9.5 & 87 & 10.2 & 157 & 9.9 \\
\hline Cancer & 42 & 5.7 & 36 & 4.2 & 78 & 4.9 \\
\hline Dementia & 73 & 10.4 & 126 & 15.5 & 199 & 13.1 \\
\hline Depression & 91 & 12.9 & 134 & 16.6 & 225 & 14.9 \\
\hline Falls in the last year & 208 & 28.1 & 238 & 28.0 & 446 & 28.0 \\
\hline ADL disability & 67 & 9.0 & 102 & 12.0 & 169 & 10.6 \\
\hline IADL disability & 203 & 27.4 & 315 & 37.3 & 518 & 32.7 \\
\hline \multicolumn{7}{|c|}{ Hospitalization in the last four years } \\
\hline None & 525 & 70.9 & 614 & 72.1 & 1139 & 71.5 \\
\hline Once & 153 & 20.7 & 134 & 15.7 & 287 & 18.0 \\
\hline Two or more times & 63 & 8.5 & 104 & 12.2 & 167 & 10.5 \\
\hline \multicolumn{7}{|l|}{ Medical visits } \\
\hline None & 332 & 44.8 & 396 & 46.5 & 728 & 45.7 \\
\hline One & 267 & 36.0 & 256 & 30.1 & 523 & 32.8 \\
\hline Two or more & 142 & 19.2 & 200 & 23.4 & 342 & 21.5 \\
\hline \multicolumn{7}{|l|}{ Bedridden } \\
\hline No & 684 & 92.3 & 761 & 89.3 & 1445 & 90.7 \\
\hline Yes & 57 & 7.7 & 91 & 10.7 & 148 & 9.3 \\
\hline \multicolumn{7}{|l|}{ Self-perceived health status } \\
\hline Good, very good & 435 & 61.0 & 471 & 57.0 & 906 & 58.8 \\
\hline Worse, bad, or regular & 278 & 39.0 & 356 & 43.0 & 634 & 41.2 \\
\hline \multicolumn{7}{|l|}{ Home health care } \\
\hline No & 715 & 96.5 & 767 & 90.2 & 1482 & 93.2 \\
\hline Yes & 26 & 3.5 & 83 & 9.8 & 109 & 6.9 \\
\hline
\end{tabular}

MMWs: monthly minimum wages; ADL: activities of daily living; IADL: instrumental activities of daily living. 


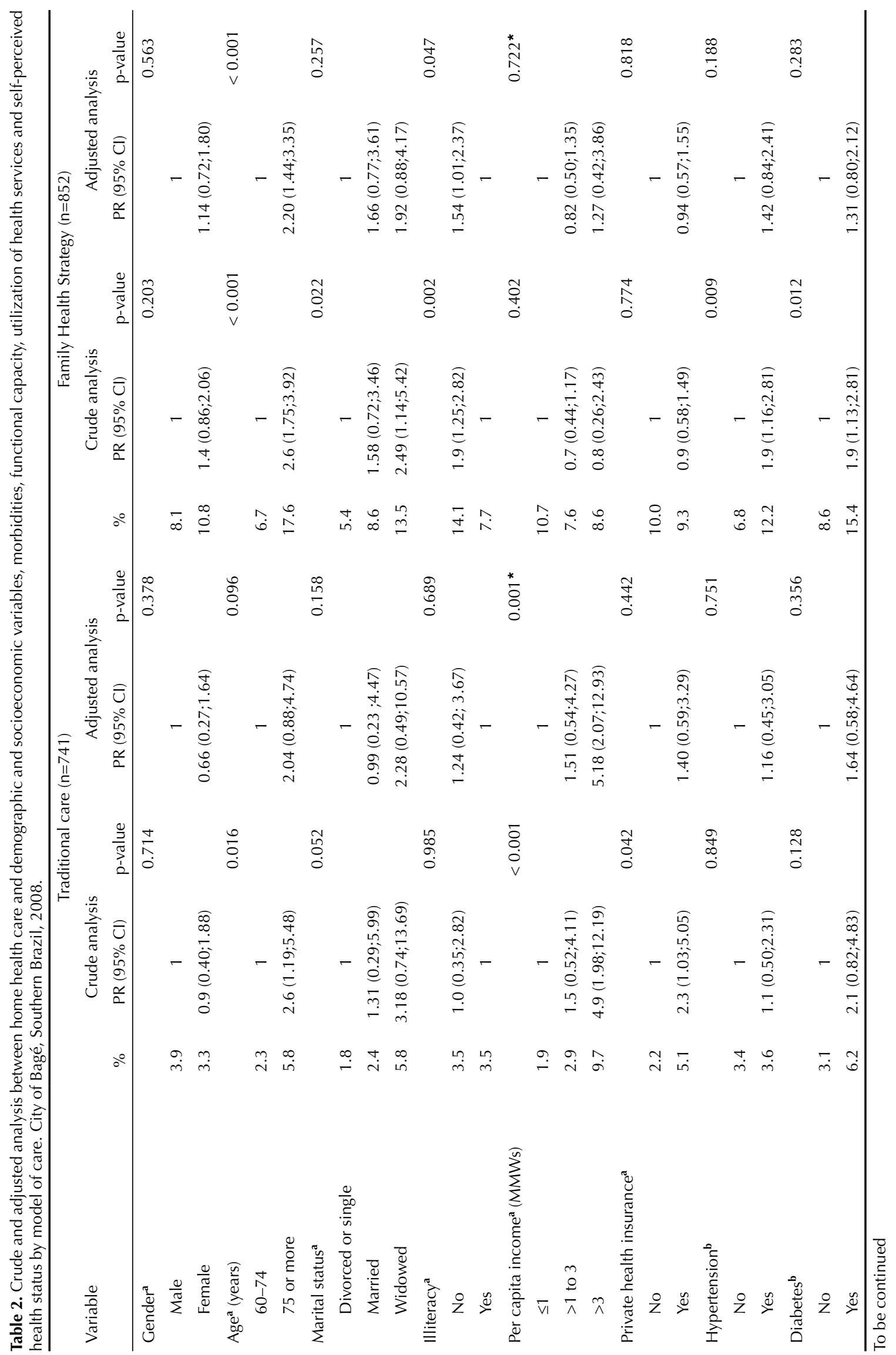




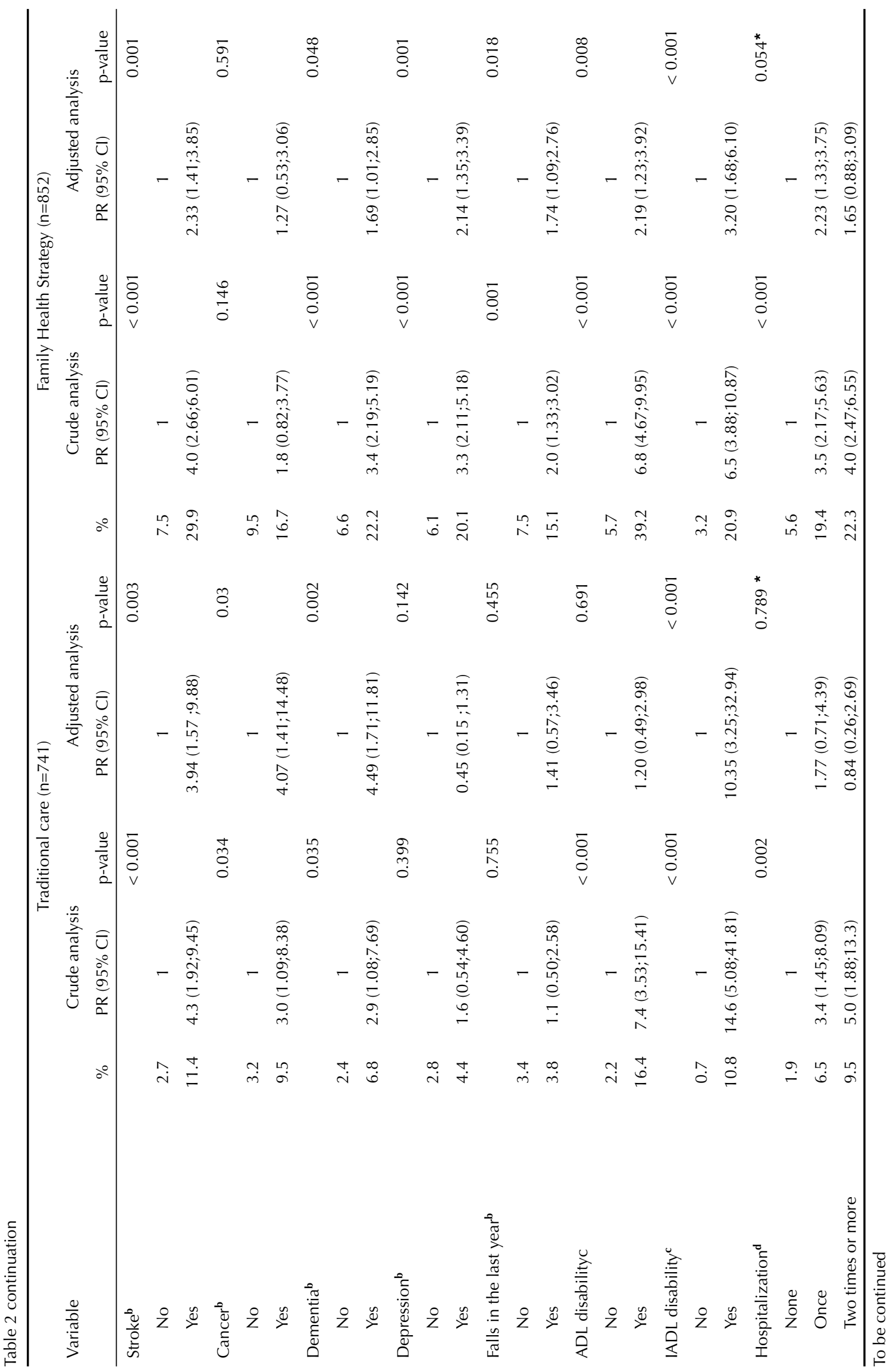




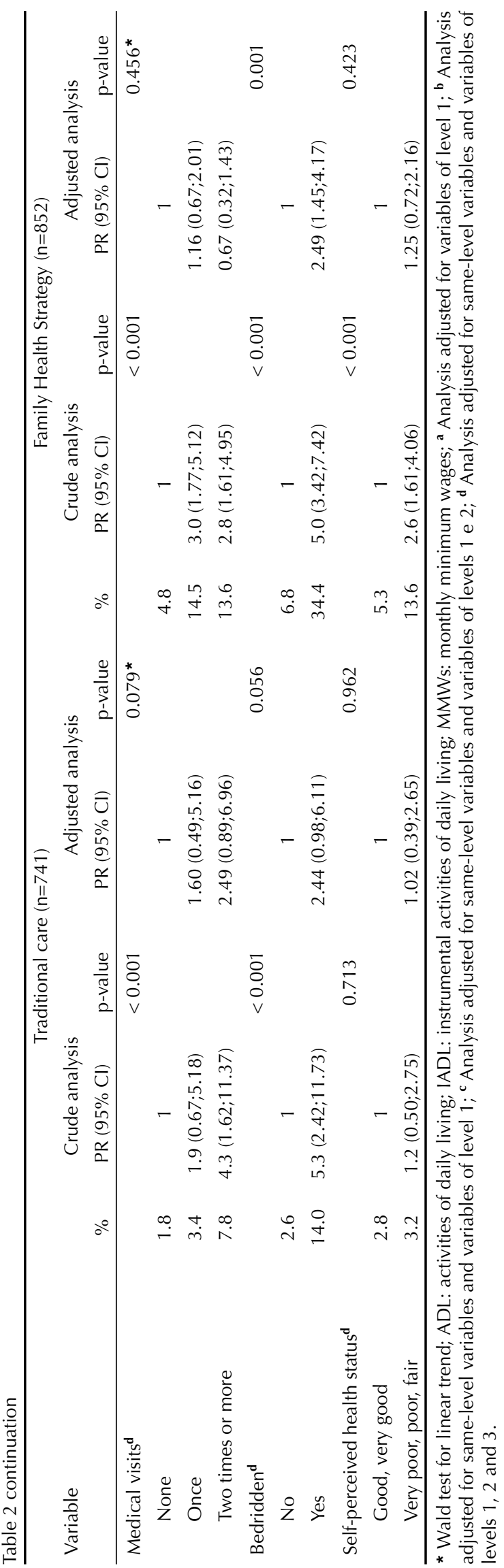

related to home health care characteristics, we chose to present data in a descriptive manner, without resorting to hypothesis testing. Data analysis was performed using Stata, version 10.0.

The study was approved by the Research Ethics Committee of Faculdade de Medicina da Universidade Federal de Pelotas (Protocol No. 15/08, 2008). Ethical principles were followed and all participants signed an informed consent form.

\section{RESULTS}

We identified 1,713 elderly, of which 1,593 participated in the study. The response rate was $93 \%$ with $4 \%$ losses and $3 \%$ refusals.

Women accounted for about two thirds of the sample. A third was widowed and $50 \%$ were married or living with a partner. Among those receiving traditional health care, a higher proportion were 75 years old or more, earned more than three MMWs and had private health insurance. In both models of care, traditional and FHS, the elderly had similar prevalence of medical diagnosis of hypertension (55\%), stroke (10\%) and history of falls in the last year (28\%). Those who received FHS care had higher rates of diabetes, dementia, depression; disability in basic and instrumental activities of daily living; history of hospitalization in the last four years; and being bedridden in the last 30 days. Overall, in both models of care, about $41 \%$ of the elderly negatively rated their health status. The prevalence of home health care was $4 \%$ and $10 \%$ in areas of traditional and FHS care, respectively (Table 1).

In the crude analysis, in both areas, home health care was statistically associated with age, prior history of stroke, dementia, disability in basic and instrumental activities of daily living; hospitalization in the last four years; medical visits in the last three months, and being bedridden in the last 30 days. In areas of traditional care, being widowed, with an income greater than three MMWs, private health insurance and history of cancer increased the likelihood of receiving home health care. In FHS areas, home care was higher among illiterate elderly with a medical diagnosis of hypertension, diabetes, signs of depression, history of falls in the last year and self-perceived health status as worse, bad or regular (Table 2).

After adjustment in areas of traditional care, income remained positively associated with care. Those with an incomes grater than three MMWs were 5.2 times more likely to receive home health care compared to those with up to one minimum wage. This likelihood was four times higher among those elderly with history of stroke, cancer and signs of dementia. Those with functional disabilities in activities of daily living were 10.4 times more likely to receive health care at home compared to those with no disability (Table 2). 
After adjustment in areas of FHS care, the likelihood of receiving home health care increased by 2.2 times for those aged 75 or more. Those illiterate were $50 \%$ more likely to receive home care. History of stroke, signs of dementia, depression, history of falls and presence of functional disability remained significantly associated with home health care after adjustment. The likelihood of receiving home health care was 3.2 times higher for those with disability in instrumental activities of daily living. Being hospitalized at least once in the last four years and bedridden in the last 30 days increased 2.2 and 2.5 times the likelihood of receiving home care, respectively. Self-perceived health status lost its association with the outcome after adjustment (Table 2).

Regardless of the care model, the family requested home health care in $75 \%$ of cases (traditional care: $n=19 / 25$; FHS care: $n=45 / 60$ ), followed by neighbors or friends $(10 \%)$. The request was made by the elderly himself/herself in $16 \%$ in traditional care areas $(n=4 / 25)$ and $3 \%$ in FHS areas $(n=2 / 60)$. Service request was made by phone in $49 \%$ of cases $(n=42 / 85)$ at a different proportion in both areas (traditional $=76 \%$; FHS $=38 \%$ ). In FHS areas, service was requested through $\mathrm{CHW}$ in $23 \%$ of cases $(n=14 / 60)$. In both models of care, services were provided in less than 24 hours in $78 \%$ $(n=60 / 77)$.

Medical doctors were involved in about $40 \%$ of visits (traditional=10/26; FHS=34/83). Nursing staff were involved in 70\% $(n=59 / 83)$ in FHS areas and 35\% $(n=9 / 26)$ in traditional care areas. Social workers were involved in $12 \%$ of visits $(n=10 / 83)$ in FHS areas and in one visit in traditional care areas. Physical therapists provided care $27 \%$ of visits $(n=7 / 26)$ in traditional areas and $4 \%(n=3 / 83)$ in FHS areas.

The assessment of care and services was similar regardless of the care model. Care was "very good" in $53 \%(n=51 / 96)$ and "good" in $42 \%(n=40 / 96)$ of the elderly studied. After care, $21 \%$ of the elderly $(n=20 / 94)$ reported that their health status remained the same, 37\% $(n=35 / 94)$ reported that it improved a little, and 29\% $(n=27 / 94)$ that it improved a lot. Recovery was reported in $13 \%(n=12 / 94)$ of cases.

\section{DISCUSSION}

Different factors were associated with home health care among the elderly studied. However, regardless of the care model, these factors are consistent with indicators set as priority in the Brazilian National Health Policy for the Elderly ${ }^{\mathrm{b}}$ and World Health Organization recommendations. ${ }^{\mathrm{c}}$ Common factors included history of stroke, signs of dementia and disability in instrumental activities of daily living. In FHS areas, a greater proportion of factors were associated with age, education level, depression, history of falls in the last year, disability in basic activities of daily living, hospitalization and being bedridden.

Care provided in FHS was able to reduce social inequities. In these areas, a higher prevalence of home health care provided to elderly with per capita income up to one minimum monthly wage and with no health insurance suggests that FHS allowed reduce in the short run inequality in health service access. A positive association with income in traditional care areas was also reported in an American study on the utilization of formal and informal care among elderly with functional disabilities. ${ }^{11}$ However, this association was not found in FHS areas, which reinforces the importance of demographic factors and conditions that can potentially cause functional disability for home health care provision.

The population aging issue stresses longer longevity with independence. Conditions such as stroke sequelae are markers of the need for care. They are preventable with proper management of hypertension, diabetes, cardiovascular disease, combined with physical activity. Similarly, physical therapy has an important role in the recovery of movement and autonomy. In traditional care areas, those with a history of stroke were four times more likely to receive home health care compared to those with no history of stroke. In FHS areas, they were 2.3 times more likely to receive care.

In the city of Bagé, signs of dementia were a major marker of home health care, regardless of area of residence. Given the large number of conditions associated with aging, the older elderly would be more likely to need home health care and dementia is a major factor in planning care in this population group. ${ }^{14}$ In FHS areas, age ( 75 years or more) and signs of dementia were factors associated with home health care, even after adjustments for demographic, socioeconomic and morbidity variables. In Spain, sequelae of stroke and dementia accounted for $43 \%$ and $27 \%$, respectively, of the demand for care in the first year of operation of a support team for home health care for elderly. ${ }^{16}$

Another important cause of immobility is the history of falls. Health providers should develop initiatives to reduce falls. In the present study, the prevalence of falls was similar $(28 \%)$ in both care areas; however, after adjustment, it remained associated with home health care only in FHS areas. A study with individuals aged 65 or more living in the South and Northeast Brazil reported a $35 \%$ prevalence of falls. Among the elderly who have suffered falls, $12 \%$ had fractures, reinforcing its importance from a public health perspective. ${ }^{20}$

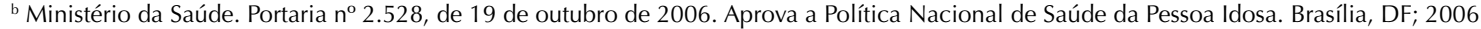
c Organização Mundial da Saúde. Envelhecimento ativo: uma política de saúde. Brasília, DF; 2005 [cited 2010 Jun 25]. Available from: http:// www.prosaude.org/publicacoes/diversos/envelhecimento_ativo.pdf
} 
Among the providers involved with care, it should be noted the great involvement of nursing staff in FHS areas. In countries where the aging process has been longer, nurses play a central role in the management of home care. ${ }^{8}$ In Brazil, the management of home health care should include a multidisciplinary care team comprising doctors, nurses, physical therapists, social workers, nutritionists, psychologists, speech therapists, occupational therapists, pharmacists, nursing assistants, and also train these providers to deal with this new demographic and epidemiological reality including home as a setting for providing care. ${ }^{1}$

The family has a major role in making home health care feasible. However, given current changes in family structure, future generations will likely require additional care that the family will not be able to provide. This will increase the involvement of the State, especially at the municipal level where home health care is provided.

The number of losses may be a limitation of the study, especially regarding answers to the variables who requested care, how the request was made, and waiting time. Still, there was a pattern that could be further explored.
The study findings suggest that home health care provision was adequate, strengthening the factors set as priority in the Brazilian National Health Policy for the Elderly. The fact that the prevalence of home health care is higher in the FHS is consistent with the socioeconomic and morbidity profile of the population attended and service provision in these areas. This strategy allowed access to care, stressing its importance for providing care to those people who are unable to get to health services. Users' satisfaction with the care received is an indicator of quality of care.

The proportion of elderly caregivers to other elderly tends to grow as life expectancy increases. ${ }^{17}$ Social support network and adequacy of home environment should be further investigated. Promotion of physical activity can improve people's balance and gait and reduce the risk of falls. Projects that assess urban infrastructure in terms of transportation, traffic, accessibility to public buildings and recreational areas may help create environments that facilitate movement of elderly people with disabilities and reduce their dependence. This set of initiatives should be developed using interdisciplinary and intersectoral approaches for building environments free of architectural barriers and appropriate to future generations. 


\section{REFERENCES}

1. Amaral NN, Cunha MCB, Labronici RHD, Oliveira ASB, Gabbai AA. Assistência domiciliar à saúde (Home Health Care): sua história e sua relevância para o sistema de saúde atual. Rev Neurociencias. 2001;9(3):111-17.

2. Barros AJ, Hirakata VN. Alternatives for logistic regression in cross-sectional studies: an empirical comparison of models that directly estimate the prevalence ratio. BMC Med Res Methodol. 2003;3:21. DOI:10.1186/1471-2288-3-21

3. Carvalho JA, Garcia RA. O envelhecimento da população brasileira: um enfoque demográfico. Cad Saude Publica. 2003;19(3):725-33. DOI:10.1590/ S0102-311X2003000300005

4. Crimmins EM. Trends in the health of the elderly. Annu Rev Public Health. 2004;25:79-98. DOI:10.1146/ annurev.publhealth.25.102802.124401

5. Duarte YAO, Diogo MJDE. Atendimento domiciliar: um enfoque gerontológico. São Paulo: Atheneu; 2000.

6. Feuerwerker LM, Merhy EE. A contribuição da atenção domiciliar para a configuração de redes substitutivas de saúde: desinstitucionalização e transformação de práticas. Rev Panam Salud Publica. 2006;24(3):180-9.

7. Folstein MF, Folstein ES; McHugh PR. "Mini-mental state". A practical method for grading the cognitive state of patients for the clinician. J Psychiatr Res. 1975;12(3):189-98. DOI:10.1016/00223956(75)90026-6

8. Hamilton DB. No place like home. Rev Am Hist. 2002;30(2):310-5. DOI:10.1353/rah.2002.0031

9. Kalache A, Kickbush I. A global strategy for healthy ageing. World Health. 1997;4-5.

10. Katz S, Ford AB, Moskowitz RW, Jackson BA, Jaffe MW. Studies of illness in the aged. The index of ADL: a standardized measure of biological and psychosocial function. JAMA. 1963;185:914-9.

11. Kemper $P$. The use of formal and informal care by the disabled elderly. Health Serv Res. 1992;27(4):421-51.

12. Kerber NPC, Kirchhof ALC, Cezar-Vaz MR. Considerações sobre a atenção domiciliária e suas aproximações com o mundo do trabalho na saúde.
Cad Saude Publica. 2008;24(3):485-93. DOI:10.1590/ S0102-311X2008000300002

13. Lawton MP, Brody EM. Assessment of older people: self-maintaining and instrumental activities of daily living. Gerontologist. 1969;9(3):179-86.

14. Lindsay J, Sykes E, McDowell I, Verreault R, Laurin D. More than the epidemiology of Alzheimer's disease: contributions of the Canadian Study of Health and Aging. Can J Psychiatry. 2004;49(2):83-91.

15. Rehem TCMSB. Assistência domiciliar em saúde: subsídios para um projeto de atenção básica brasileira. Cien Saude Colet. 2005;10(Suppl):231-42. DOI:10.1590/S1413-81232005000500024

16. Requena López A, Moreno Mateo R, Torrubia Atienza P, Rodeles del Pozo R, Mainar García P, Moliner Izquierdo MA. Análisis de la demanda de actuación de un equipo de soporte de atención domiciliaria (ESAD). Aten Primaria. 2001;28(10):652-56.

17. Rosa TEC. Redes de apoio social. In: Litvoc J, Brito FC, editors. Envelhecimento: prevenção e promoção da saúde. São Paulo: Atheneu; 2004. p.203-18.

18. Sheikh JI, Yesavage JA. Geriatric Depression Scale (GDS): recent evidence and development of a shorter version. New York: Hayworth; 1986.

19. Silva KL, Sena R, Leite JCA, Seixas CT, Gonçalves AM. Internação domiciliar no Sistema Único de Saúde. Rev Saude Publica. 2005;39(3):391-7. DOI:10.1590/ S0034-89102005000300009

20. Siqueira FV, Facchini LA, Piccini RX, Tomasi E, Thumé E, Silveira DS, et al. Prevalência de quedas em idosos e fatores associados. Rev Saude Publica. 2007;41(5):749-56. DOI:10.1590/S003489102007000500009

21. Veras R. Envelhecimento populacional contemporâneo: demandas, desafios e inovações. Rev Saude Publica. 2009;43(3):548-54. DOI:10.1590/ S0034-89102009005000025

22. Viana ALD, Dal Poz MR. A reforma do sistema de saúde no Brasil e o Programa de Saúde da Família. Physis. 2005;15(Suppl.):225-64. DOI:10.1590/S010373312005000300011

The authors declare that there are no conflict of interest. 